\title{
Application of low field nuclear magnetic resonance technique to characterize the mass transfer of corrosion inhibitors in concrete
}

\author{
L. Bu, X. Wang, N. Song and Z. Liu* \\ School of Civil Engineering, Yantai University, Yantai, 264005, China \\ "E-mail: $\underline{\text { zzy1698@163.com }}$
}

\begin{abstract}
A green aqueous product named PCI-2016 has been developed by using multicompound and chelate-induced techniques recently. The mass transfer process of the product in concrete by using low field nuclear magnetic resonance technique was carried out. The one-dimensional saturated capillary absorption experiment of specimens immersed in PCI-2016 were carried out. The variation of the absorbed mass and penetrating height of the PCI-2016 with time was observed. The results indicated that the absorbed mass and penetrating height of PCI-2016 increased with the increase of time, and the initial growth rate in $24 \mathrm{~h}$ is the larger and then tends to gentle. The saturation of PCI-2016 in test block at different ages and positions was calculated by frequency coding which is collected by using low field nuclear magnetic resonance experiment. The variation of PCI-2016 saturation at different depths from the surface with time can also be calculated by the modified MCI transport model. Compared with the results, the numerical results are in good agreement with the experimental results. So the low field nuclear magnetic resonance can be used to measure the transport process of PCI-2016 in cement-based materials. It provided a reference for characterizing the mass transfer process of corrosion inhibitor in concrete.
\end{abstract}

Keywords: modified transfer model, low field nuclear magnetic resonance (NMR), one dimensional saturated capillary absorption, migrating corrosion inhibitor (MCI).

Received: December 13, 2018. Published: February 1, 2019

doi: $\underline{10.17675 / 2305-6894-2019-8-1-8}$

\section{Introduction}

Steel corrosion is an important reason for concrete structures destruction in chloride environment, which has caused huge economic losses in the past few years in the world [1]. Finding effective methods to prevent and inhibit the corrosion of reinforced concrete structures has become a hot topic. Due to non-damage, economic and effective anti-corrosion performance, surface-painting migrating corrosion inhibitor (MCI) has attracted the attention of researchers all over the world [2-7]. 
In previous studies, the transport and anti-corrosion mechanism of MCI in chloride solution and concrete structures, as well as the influence of the MCI molecule on anti-corrosion performance have been reported [8]. The modified transport models [9] of reactive and non-reactive $\mathrm{MCI}$ in concrete structure have been established on the basis of the water transport model [10] in concrete. According to a large number of electrochemical and microscopic tests results, the tested MCIs show good transport performance in concrete specimens, by which the MCI can penetrate into the cover concrete and then arrive at the surface of steel bars. The dense film of MCI molecules formed on the steel bar surface may protect steel bar from the chloride corrosion [11]. The tested product named PCI-2015 had been applied in the engineering of durability rehabilitation for concrete structures [12]. In recent years, the mechanism and effects of migrating corrosion inhibitors have been extensively studied [13-18]. However, not so much works focused on the mass transfer process of migrating corrosion inhibitors in concrete. The transport mechanism and transport law of MCI in concrete is of great significant to optimization design of MCI composition and improving the transport rate and inhibiting efficiency of MCI in concrete. Recently, a green aqueous organic product named PCI-2016 has been developed by using multicompound and chelate-induced techniques, and it has been proved that PCI-2016 could prevent corrosion [8]. The mass transfer process of the product in concrete by using low field nuclear magnetic resonance technique $[19,20]$ was carried out.

\section{Experimental}

\subsection{Materials}

Concrete specimens were made with Portland cement (P.I 52.5), Chinese standard sand and potable city water. The chemical composition of cement is listed in Table 1 . The bending strength of cement at 3 days and 28 days were $6.4 \mathrm{MPa}$ and $9.1 \mathrm{MPa}$, respectively. The compressive strength of cement at 3 days and 28 days were $29.7 \mathrm{MPa}$ and $61.5 \mathrm{MPa}$, respectively. The water to cement ratios (W/C) of specimens was 0.55 . The sand to cement ratio was 3.0. In order to gain a similar fluidity, super-plasticizer was added in the concrete. The size of specimens was $40 \mathrm{~mm} \times 40 \mathrm{~mm} \times 160 \mathrm{~mm}$. A aqueous penetrating corrosion inhibitor marked PCI-2016 prepared by using multicompound and chelate-induced techniques was used in the experiments.

Table 1. The chemical composition of cement.

\begin{tabular}{cccccccc}
\hline Composition & $\mathbf{S i O}_{2}(\mathrm{~S})$ & $\mathrm{Fe}_{2} \mathrm{O}_{\mathbf{3}}(\mathrm{F})$ & $\mathrm{Al}_{2} \mathbf{O}_{3}(\mathrm{~A})$ & $\mathbf{C a O}(\mathrm{C})$ & $\mathrm{MgO}(\mathrm{M})$ & $\mathrm{SO}_{3}(\mathrm{~S})$ & Others \\
\hline Content $(\%)$ & 21.63 & 3.6 & 3.95 & 64.68 & 2.99 & 2.01 & 1.13 \\
\hline
\end{tabular}




\subsection{Transport experiments}

Four transversal surface of concrete specimens were initially sealed by structural adhesive, the two ends of specimens (about $30 \mathrm{~mm}$ from the end) were cut and the remaining specimen specimen (the length was about $100 \mathrm{~mm}$ ) were used for the test specimens. Then specimens specimens were dried in an oven at $50^{\circ} \mathrm{C}$ until a constant mass was obtained. After the specimens cooling down to about $20^{\circ} \mathrm{C}$, one end of the specimens were exposed to $\mathrm{MCI}$ in plastic sealed boxes and the immersing depth was $2 \mathrm{~mm}$ during the test. The weights of absorbed MCI were measured after different time such as $1 \mathrm{~d}, 2 \mathrm{~d}, 3 \mathrm{~d}, 4 \mathrm{~d}$ and $5 \mathrm{~d}$. The mass mass of PCI-2016 $\left(W_{\mathrm{a}}\right)$ in the concrete specimen was measured according the following equation:

$$
W_{\mathrm{a}}=\left(m_{\mathrm{t}}-m_{0}\right) / m_{\mathrm{t}}
$$

Where, $m_{\mathrm{t}}$ is the weight of specimen at different transport time, $\mathrm{g} ; m_{0}$ is the initial weight of dried specimen, $g$.

\subsection{Low field nuclear magnetic resonance test}

The magnetic field strength below $0.5 \mathrm{~T}$ is low field nuclear magnetic resonance (LF-NMR), which is mainly used to detect the physical properties of materials. The principle of LF-NMR is that different substances have different relaxation times. And the relaxation time of the same substance in different phase states is different. Low-field NMR technique is a rapid non-destructive detection method. It is sensitive to analyze sample's physical character for water's nature of pervasive as probes. Characterizing the mass transfer process of samples in PCI-2016 is the first attempt of nuclear magnetic resonance technology in the field of MCI.

The Macro MR12-150H large size magnetic resonance imaging analyzer (Niumag Analytical Instrument Corporation) was used for testing the transport of MCI in concrete specimens. The testing parameters are as follows: the resonance frequency was $12.797 \mathrm{MHz}$, magnetic intensity was $0.3 \mathrm{~T}$, coil diameter was $100 \mathrm{~mm}$, and the magnet temperature was $32^{\circ} \mathrm{C}$. Fast imaging was performed using the plane perpendicular to the saturation surface as the imaging projection plane. The images of penetrating heights of PCI-2016 in concrete specimens at different times could be obtained by this method. Moreover, the saturation for PCI-2016 in specimens at different times and different heights could be calculated by frequency codes obtaining from the low field nuclear magnetic resonance test.

\section{Transport model}

Based on former study of Liu et al. [11], the transport process of reactive MCI in cement-based materials can be simulated by the modified MCI transport model. $D(S)$ is the equivalent permeability coefficient of MCI in transport model. $D(S)$ of reactive MCI can be calculated by the following equation: 


$$
D(S)=\varphi(S)^{\alpha}(1-S)^{\beta} \frac{1}{\rho_{1} \varphi(s)}\left[\frac{K}{g}+D_{\mathrm{Mv}} \frac{M \rho_{\mathrm{v}}}{\rho_{1} R T}\right] \times \frac{2 B \gamma}{[\ln (1-S)]^{2}(1-S)}
$$

In equation (2), $\varphi(S)$ is concrete porosity; $S$ is variable liquid phase saturation of MCI in concrete; $D_{\mathrm{Mv}}$ is the equivalent diffusive coefficient of MCI in gaseous phase in concrete $\left(\mathrm{m}^{2} / \mathrm{s}\right) ; R$ is the perfect gas constant $(\mathrm{J} / \mathrm{mol}) ; M$ is the molar mass of inhibitor $(\mathrm{kg} / \mathrm{mol}) ; T$ is the absolute temperature of environment $(\mathrm{K}) ; \gamma$ is the surface tension of inhibitor $(\mathrm{mN} / \mathrm{m}) ; K$ is permeability coefficient of inhibitor in liquid phase in concrete $(\mathrm{m} / \mathrm{s}) ; g$ is the gravitational acceleration $(\mathrm{N} / \mathrm{kg}) ; B$ is the peak value of pore distribution in concrete; when $W / C$ is 0.55 , the $B$ value is $9.6 \times 10^{6} ; \rho_{\mathrm{l}}, \rho_{\mathrm{v}}$ are the density of inhibitor in liquid and gaseous phase respectively $\left(\mathrm{kg} / \mathrm{m}^{3}\right) ; \alpha, \beta$ were coefficients fitted by experimental data. For PCI-2016 the parameters are as follows: $\rho_{\mathrm{l}}=0.989 \mathrm{~kg} / \mathrm{m}^{3} ; \rho_{\mathrm{v}}=0.216 \mathrm{~kg} / \mathrm{m}^{3} ; \gamma=37.4 \mathrm{mN} / \mathrm{m} ; \mu=$ $0.005 \mathrm{~Pa} \cdot \mathrm{s}$ ( $\mu$ is the dynamic viscosity coefficient); $D_{\mathrm{Mv}}=8.9 \times 10^{-6} \mathrm{~m}^{2} / \mathrm{s}$.

Combining the transport equation (2) and the initial boundary conditions, it is concluded that the equation of PCI-2016 one-dimensional transmission in the sample is equation (3):

$$
\left\{\begin{array}{c}
\frac{\partial S_{\mathrm{M}}}{\partial t}=\frac{\partial\left(D\left(S_{\mathrm{M}}\right) \frac{\partial S_{\mathrm{M}}}{\partial x}\right)}{\partial x} \\
S_{\mathrm{M}}(x, t=0)=S_{\mathrm{Mini}} \\
S_{\mathrm{M}}(x=0, t>0)=S_{\mathrm{Ms}}
\end{array}\right.
$$

In equation (3), $S_{\mathrm{Mini}}$ is the initial saturation of concrete; $S_{\mathrm{M}}=S_{\mathrm{M}}(x, t)$ represents the distribution of PCI-2016 saturation at the surface $x$ of the sample when the time is $t ; S_{\mathrm{Ms}}$ is the fixed saturation of concrete boundary ; $t$ is the total transmission time (min); a single point subdomain precise integration method with good stability and high accuracy is used to solve the transmission equation, and the numerical calculation is carried out by MATLAB:

$$
S_{\mathrm{M}, x}^{t}=\mathrm{e}^{-2 r D\left(S_{\mathrm{M}}\right)} S_{\mathrm{M}, x}^{t-1}+\frac{1}{2}\left(1-\mathrm{e}^{-2 r D\left(S_{\mathrm{M}}\right)}\right)\left(S_{\mathrm{M}, x+1}^{t-1}+S_{\mathrm{M}, x-1}^{t-1}\right)
$$

In equation (4), $r=\Delta t /(\Delta x)^{2}$.

\section{Experimental results and discussions}

\subsection{Absorbed mass and penetrating height}

Figure 1 and Figure 2 are the temporal variations of the absorbed mass and penetrating height of the specimen in the PCI-2016. As it can be seen from Figure 1, the absorbed mass of PCI-2016 in the specimen increases greatly at the beginning of the experiment and tends to be slow at the later stage. In Figure 2, in the first day, the penetrating height of 
PCI-2016 in the specimen increases to $10.2 \mathrm{~mm}$, the penetrating height tends to be stable at $40 \mathrm{~mm}$ at fifth days, and the trend of the later growth is also slow. Figure 1 and Figure 2 show the same pattern.

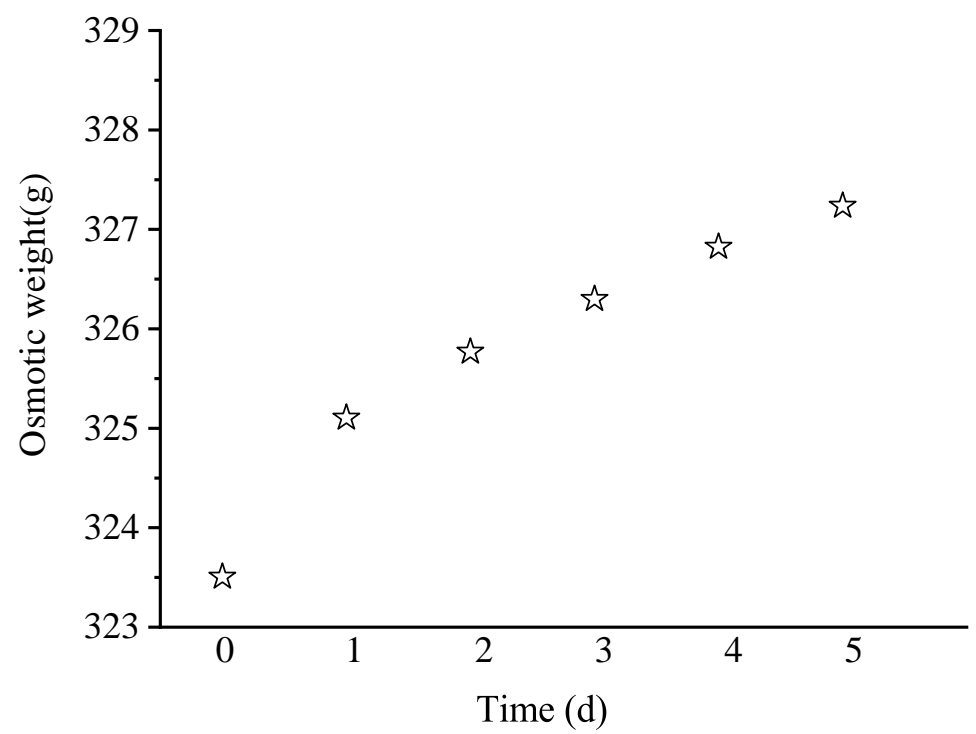

Figure 1. The temporal variations of the absorbed mass of the specimen in the PCI-2016 at five days.

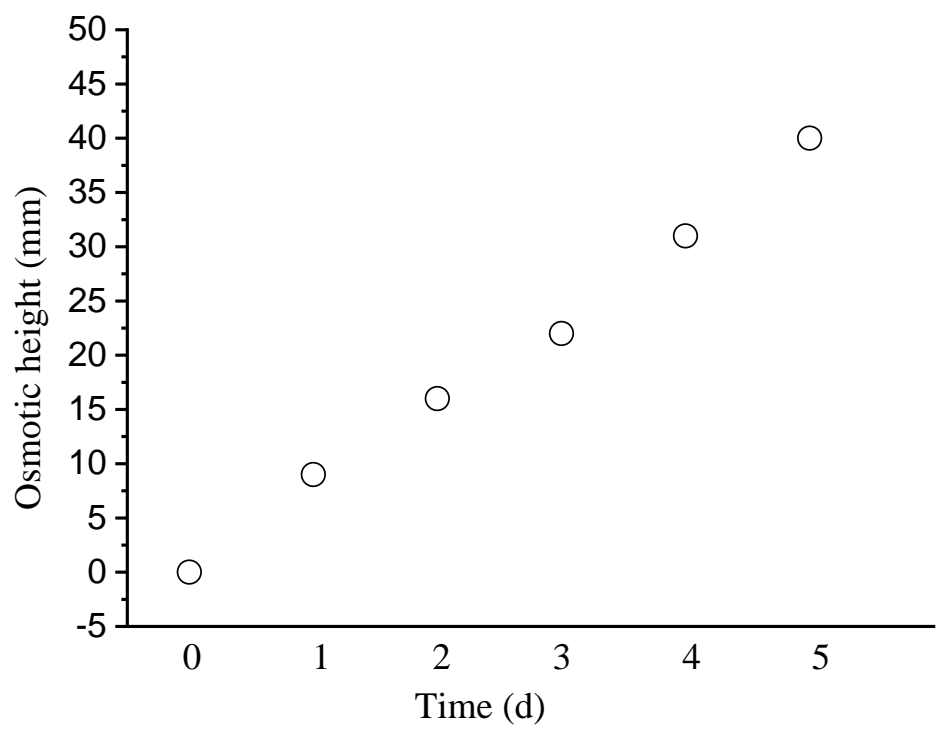

Figure 2. The temporal variations of the penetrating height of the specimen in the PCI-2016 at five days. 


\subsection{Moisture distribution images from low field NMR}

Figure 3 is the images of penetrating height obtained by low field NMR experiments. It can be seen from Figure 3 that the penetrating height of water varies with time. The results showed that penetrating heights of PCI-2016 in specimens increase with the increase of absorbing time.
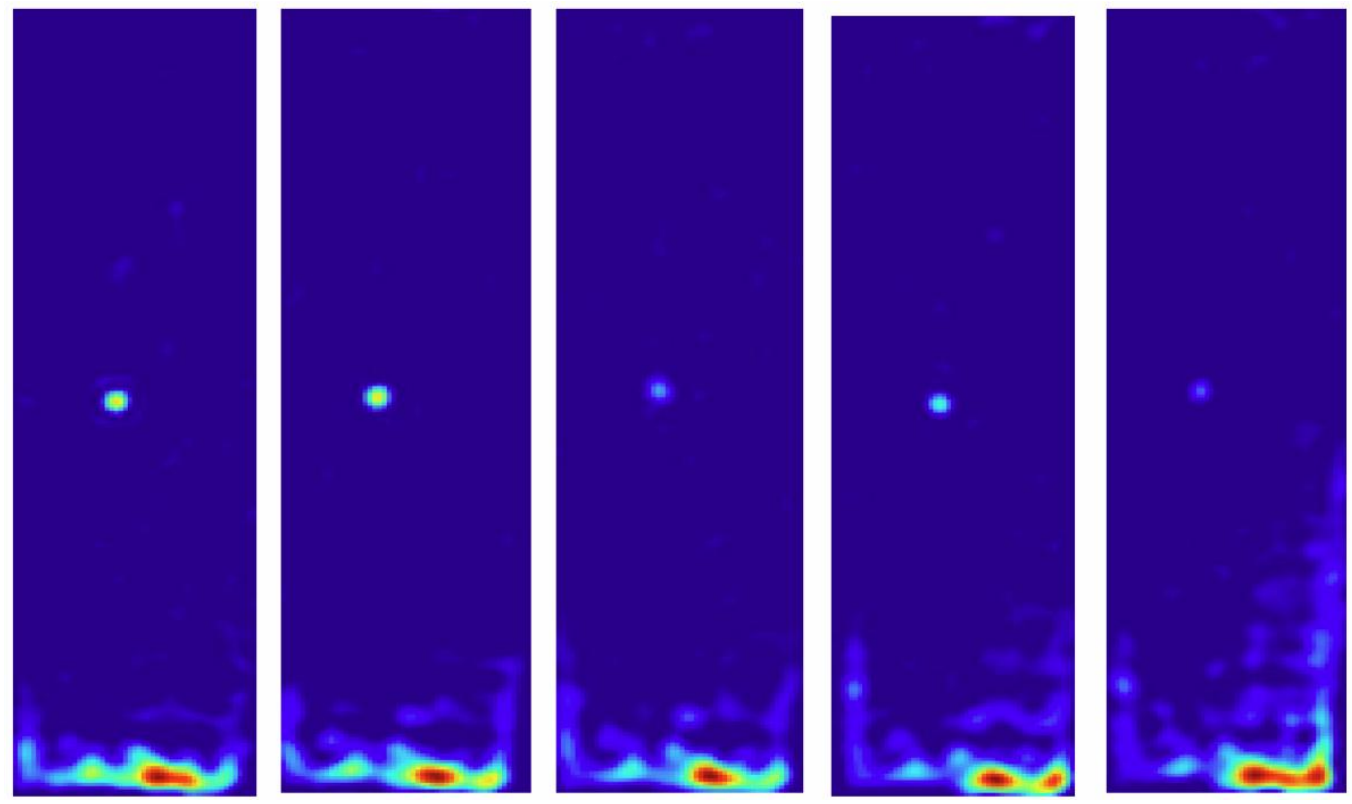

Figure 3. Pseudo color map of moisture distribution in specimen (From left to right the testing days are $1 \mathrm{~d}, 2 \mathrm{~d}, 3 \mathrm{~d}, 4 \mathrm{~d}$ and $5 \mathrm{~d}$, respectively).

\subsection{Saturation in specimen}

Figure 4(a) shows the changes of PCI-2016 saturation in specimen in different days at different locations calculated by the frequency codes gained from low field NMR experiments. Figure 4(b) is the PCI-2016 saturation in specimen calculated by the transport model. As seen in these two figures, the saturation of PCI-2016 in each layer is increase with the increase of absorbing time. And the calculated results are in close compliance with the experimental results from the NMR tests, which indicating that this liquid phase transport model is suitable for simulating the one-dimensional saturated absorption transport process of PCI-2016 in concrete.

\section{Conclusions}

The variation of the absorbed mass and penetrating height of the PCI-2016 with time was investigated by carrying out one-dimensional saturated capillary absorption experiment of specimens immersed in PCI-2016. Results showed that with the increase of permeation time, absorbed mass and penetrating height of PCI-2016 in the specimen increase. The absorbed mass of PCI-2016 in the specimen increases greatly at the beginning of the experiment and tends to be slow at the later stage. The penetrating height of PCI-2016 in 
the specimen increases to $10.2 \mathrm{~mm}$ on the first day, the penetrating height tends to be stable at $40 \mathrm{~mm}$ on fifth days, and the trend of the later growth is also slow. The PCI-2016 absorbed mass of absorbing tests are in close compliance with the NMR test results. And the calculated the saturation of PCI-2016 by the transport model is similar with the experimental results from the NMR tests. The results support that the one-dimensional saturated absorption transport process of PCI-2016 in concrete can be measured by the low field nuclear magnetic resonance experiment.
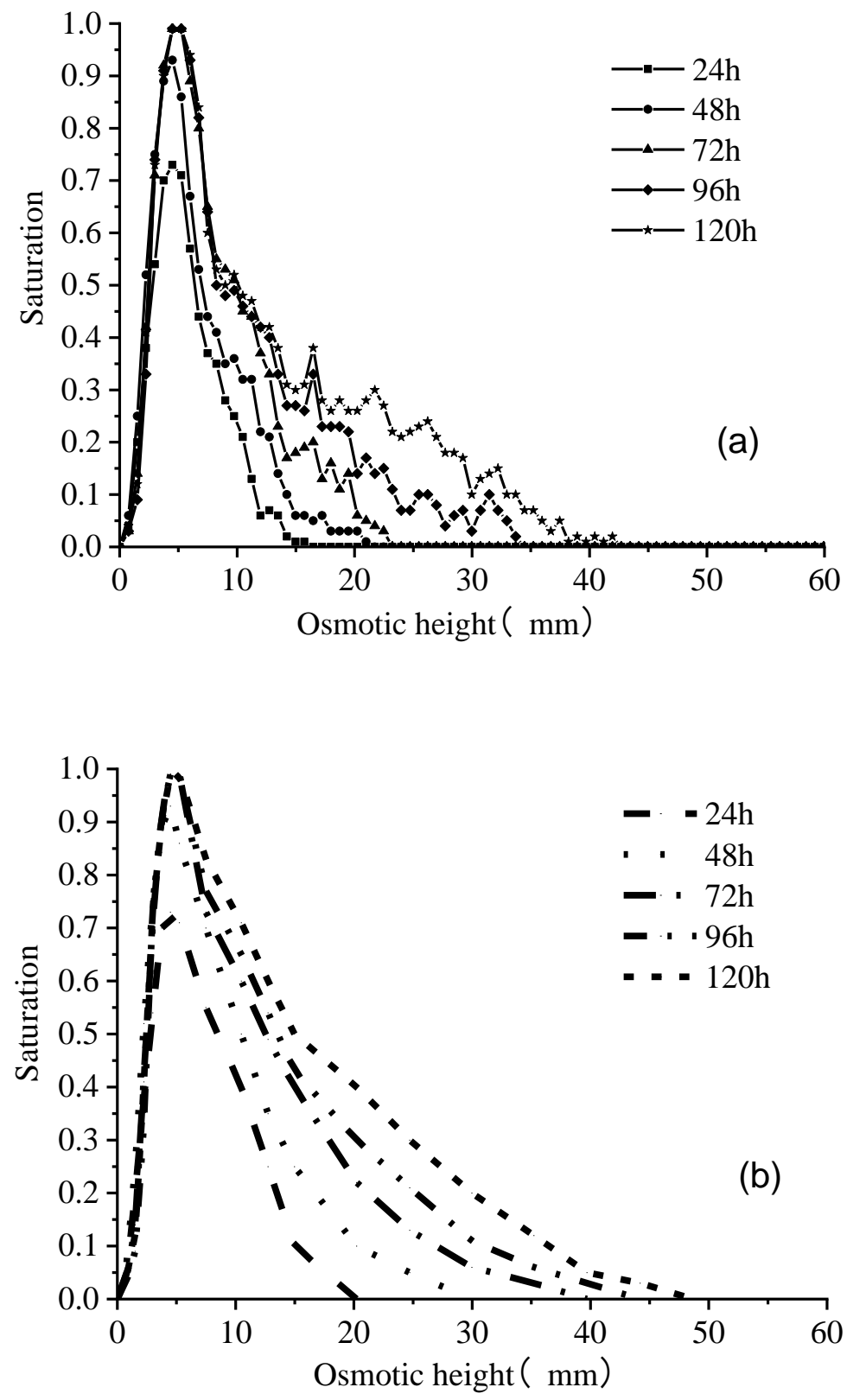

Figure 4. The variation of PCI-2016 saturation in concrete specimen at different time and different heights. (a) NMR testing results; (b) Calculated results by transport model. 


\section{Acknowledgments}

Thanks for the support of National Natural Science Foundation of China (51278443, 51678512).

\section{References}

1. L. Holloway, K. Nairn and M. Forsyth, Concentration monitoring and performance of a migratory corrosion inhibitor in steel-reinforced concrete, Cem. Concr. Res., 2004, 34, no. 8, 1435-1440. doi: https://doi.org/10.1016/j.cemconres.2004.01.019

2. M.M. Page, V.T. Ngala and C.L. Page, Corrosion inhibitors in concrete repair systems, Mag. Concr. Res., 2000, 52, no. 1, 25-37. doi: https://doi.org/10.1680/macr.2000.52. $\underline{1.25}$

3. M.S. Ibrahim, $\gamma$-rays irradiation for preparation of some organic corrosion inhibitors and production of highly adhering anti-corrosive varnishes of superior protective properties, Anti-Corros. Meth. Mater., 1996, 43, no. 4, 18-26. doi: https://doi.org/10.1108/ eb007397.

4. M. Christov and A. Popova, Adsorption characteristics of corrosion inhibitors from corrosion rate measurements, Corros. Sci., 2004, 46, 1613-1620. doi: https://doi.org/ 10.1016/j.corsci.2003.10.013

5. T.A. Levasy, C. Manically and M.G. Richardson, The effect of a new generation surface-applied organic inhibitor on concrete properties, Cem. Concr. Compos., 2007, 29, no. 5. 357-364. doi: https://doi.org/10.1016/j.cemconcomp.2006.12.013

6. B. Elsener, M. Buchler, F. Stalder and H. Böhni, Migrating Corrosion Inhibitor Blend for Reinforced Concrete: Part 1 - Prevention of Corrosion, Corrosion, 1999, 55, no. 12, 1155-1163. doi: https://doi.org/10.5006/1.3283953

7. A.U. Malik, I. Andijani and F. Al-Moaili, Studies on the performance of migratory corrosion inhibitors in protection of rebar concrete in gulf seawater environment, Cem. Concr. Compos., 2004, 26, no. 3, 235-242. doi: https://doi.org/10.1016/S0958-9465 (03)00042-8

8. Z.Y. Liu, N Song and Z.X. Wang, Properties and Characterization on a Novel Aqueous Inhibitor for Inhibiting Alloy Steel Corrosion in Chloride Solution, ASCE J. Mater. Civil Eng., 2017, 29, no. 9, 04017136. doi: https://doi.org/10.1061/(ASCE)MT.1943-5533. 0001961.

9. W.B. Yang, L. Yu, Z.Y. Liu, Z. Wang and N. Song, Quantitative model and application of migration corrosion inhibitor affecting corrosion rate of steel bar, J. Chin. Ceram. Soc., 2015, 43, no. 6, 839-844 (in Chinese). doi: https://doi.org/10.14062/j.issn.0454$\underline{5648.2015 .06 .21}$

10. Z.Y. Liu, L. Yu, Z.X. Wang and W. Yang, Modeling and experimental validation of MCI transport involving pore-blocking effect in cement-based materials, J. Mater. Civ. Eng., 2015, 28, no. 5, 04015187. doi: https://doi.org/10.1061/(asce)mt.1943-5533. $\underline{0001455}$ 
11. Z.Y. Liu, Z.X. Wang and N. Song, Optimization of migrating corrosion inhibitor and its permeability and corrosion resistance, J. Chin. Ceram. Soc., 2016, 44, no. 3, 481-486 (in Chinese). doi: https://doi.org/10.14062/j.issn.0454-5648.2016.03.22

12. Song N, Wang Z X, Liu Z Y, et al. Study on improvement of durability for reinforced concrete by surface-painting migrating corrosion inhibitor and engineering application. Mater. Sci. Eng., 2017, 167: 1-5. https://doi.org/10.1088/1757-899X/167/1/012072

13. F. Atmani, D. Lahem, M. Poelman, C. Buess-Herman and M.-G. Olivier, Mild steel corrosion in chloride environment: effect of surface preparation and influence of inorganic inhibitors, Corros. Eng., Sci. Technol., 2012, 48, no. 1, 9-18. doi: https://doi.org/10.1179/1743278212Y.0000000037

14. S.H. Yoo, Y.W. Kim, K. Chung, S.-Y. Baik and J.-S. Kim, Synthesis and corrosion inhibition behavior of imidazoline derivatives based on vegetable oil, Corros. Sci., 2012, 59, no. 3, 42-54. https://doi.org/10.1016/j.corsci.2012.02.011

15. W. Shi, T.Z. Wang, Z.H. Dong and X.-P. Guo, Application of wire beam electrode technique to investigate the migrating behavior of corrosion inhibitors in mortar, Constr. Build. Mater., 2017, 134, 167-175. doi: https://doi.org/10.1016/j.conbuildmat.2016. $\underline{12.036}$

16. F. Atmani, D. Lahem, D. Poelman, C. Buess-Herman and M.-G. Olivier, Mild steel corrosion in chloride environment: effect of surface preparation and influence of inorganic inhibitors, Corros. Eng., Sci. Technol., 2012, 48, no. 1, 9-18. doi: https://doi.org/10.1179/1743278212Y.0000000037

17. B. Elsener, M. Büchler, F. Stalder and H. Böhni, Migrating Corrosion Inhibitor Blend for Reinforced Concrete: Part 1 - Prevention of Corrosion, Corrosion, 1999, 55, no. 12, 1155-1163. doi: https://doi.org/10.5006/1.3283953

18. M.V. Diamanti, E.A.P. Rosales, G. Raffaini, F. Ganazzoli, A. Brenna, M. Pedeferri and M. Ormellese, Molecular modelling and electrochemical evaluation of organic inhibitors in concrete, Corros. Sci., 2015, 100, 231-241. doi: https://doi.org/10.1016/ j.corsci.2015.07.034

19. R. Zhang, J.X. Wang, D.N. Li, D-J. Chen, J.-H. Huo, L. Yang and X.-C. Wang, Effect of WJ-1 retarder on early hydration of cement slurry, Bull. Chin. Ceram. Soc., 2015, 11, 1001-1625 (in Chinese). doi: http://doi.org/10.16552/j.cnki.issn1001-1625.2015.11.022

20. L. Tan, C.F. Wei, H.H. Tian, J.-Z. Zhou and H.-Z. Wei, Low field NMR study on unfrozen water content in frozen soil, Rock Soil Mech., 2015, no. 06, 1000-7598. doi: https://doi.org/10.16285/j.rsm.2015.06.006 